\title{
On the question of the use of inter-settlement territories in the structure of urban agglomerations
}

\author{
Valerija Vylegzhanina ${ }^{1,2, *}$ Ilgiz Giniyatov ${ }^{2}$, Nadezhda Dobrotvorskaja ${ }^{2,3}$, Viktor Timonov ${ }^{4}$ \\ ${ }^{1}$ Federal Service of State Registration, Cadastre and Cartography for Novosibirsk region, 630091, \\ Derzhavina Str., 28, Novosibirsk, Russia \\ ${ }^{2}$ Siberian State University of Geosystems and Technologies, Plakhotnogo Str., 10, Novosibirsk, \\ Russia \\ ${ }^{3}$ Siberian Federal Scientific Center of Agrobiotechnologies RAS, Novosibirsk Region, r. p. \\ Krasnoobsk, 630501, Russia \\ ${ }^{4}$ Novosibirsk State University of Architecture, Design and Arts named after A. D. Kryachkov, \\ 630099, Krasny Prospekt, 38, Novosibirsk, Russia
}

\begin{abstract}
The article discusses the reasons that contribute to the formation of agglomerations on the territory of the Novosibirsk region, overpopulation of urban areas that make up the agglomerations, as well as the reasons for the decrease in rural inhabited space on the territory of municipalities located within the boundaries of the regions of the region, both within the agglomeration itself and on the territory districts of the region located outside the agglomeration. The results of the influence of urban agglomerations on the state of agricultural lands located within and outside the specified agglomerations are considered. An analogy is drawn between these processes in relation to agricultural lands with lands of the named category located on the territory of the Russian Federation. A possible solution to these problems is proposed, providing for the development of conceptual approaches, including the introduction of phased structural and investment measures.
\end{abstract}

\section{Introduction}

More than 20 years have passed since the beginning of the land reform in the territory of the previously existing Soviet state, the purpose of which was development of various forms of land management, the formation of a multi-structured economy by abolishing the state monopoly on land [1].

Since formation of the Russian Federation, land reform has been gaining momentum. A number of laws were adopted that allow citizens, within the framework of various organizational and legal associations, to carry out agricultural activities, which is based on the principle of preserving the intended use of land plots $[2,3]$.

The security function of the state is based on the regulation of land relations within the framework of the law, and supervisory measures are also carried out to correct these legal

\footnotetext{
* Corresponding author: pravo@uy.nsk.su
} 
relations [4]. Wherein, the current situation picture in the field of rational use of agricultural land is not in favor of the designated category of land.

Over the years, the emerging difficult socio-economic situation in the country has led to the depopulation of rural areas, the outflow of the able-bodied population to cities and overconcentration of the population in large cities and adjacent settlements [5]. This process has led to formation of urban agglomerations, concentrating the scientific, cultural potential, personnel reserve, an overabundance of the working population [6]. The reverse side of this process is, respectively, the desertification of rural areas accompanied by degradation of rural settlements and, as a consequence, their abolition. Accumulation of agricultural production near more or less "live" settlements and near urban agglomerations is accompanied by decrease in acreage and decrease in the quality of agricultural land.

The purpose of this article is to analyze modern socio-economic phenomena in intersettlement territories using the example of the Novosibirsk region. The objectives of the study were to study the influence of urban agglomerations on the state of agricultural land and rural settlements located in the territory of the Novosibirsk agglomeration.

\section{Materials and Methods}

The object of study is agricultural land located within the boundaries of the Toguchinsky district of the Novosibirsk region included in the Novosibirsk agglomeration. Within preparation and presentation of the study results, the data of the public cadastral map posted on the Federal Service of State Registration, Land Register and Mapping website; Earth remote sensing materials; official data published on the websites of Novosibirskstat, the Government of the Novosibirsk Region, the Ministry of Agriculture of the Novosibirsk Region; on the official website of the administration of the Toguchinsky district of the Novosibirsk region, the data obtained using the Google maps program, were used.

\section{Results and Discussion}

The Novosibirsk Region (NSO) is no exception to the general socio-economic picture summarized in the introduction of this article in relation to the entire Russian Federation.

Historically, the bulk of settlements in the territory of the Novosibirsk Region arose on the place of fortifications - military fortifications erected to protect immigrants from the European part of Russia in the 17th century during the development of Siberia. The main occupations of the population were arable farming, fishing, hunting and carriage. Favorable climate, large areas with fertile lands have led to the dominance of the agricultural industry throughout all time periods of development of the territory [7]. The rapid, poorly prepared implementation of the land reform of the 90 s of the last century led to an unfavorable socioeconomic situation in the agriculture of the country and the Novosibirsk region in particular, caused an outflow of the able-bodied population to large regional centers and cities of the Novosibirsk region, which in turn led to decrease in agricultural activity, increase in the area of uncultivated farmland and, as a result, degradation of agricultural land.

According to a number of decrees of the President of the Russian Federation, within the framework of regional legislative initiatives in order to stabilize the situation described above, the Government of the Novosibirsk Region has developed a strategy for the socioeconomic development of the Novosibirsk Region for the period up to 2030 (Strategy) [8].

The main direction of the Strategy is formation of urban agglomerations and territories of advanced socio-economic development (TASED) in NSOs. The largest urban agglomeration is Novosibirsk one, which includes 7 districts of the region, 4 cities and 1 village. The Novosibirsk agglomeration is formed on the basis of the principle of the spatial organization 
of the region: the city of Novosibirsk and the cities of the region located near it, which are most susceptible to its influence [8]. In the territory of the agglomeration, two TASED are formed - this is industrial community Linevo of Iskitimsky district and industrial community Gorny of Toguchinsky district, which are monocities, within the boundaries of which it is planned to create new city-forming enterprises with an increase in the number of jobs [8].

The object of this study is agricultural land within the Toguchinsky district of the Novosibirsk region, located between the village of Lnikha and the village of Borovushka, which are part of the Repyevsky village council of the Toguchinsky district of the NSO. The village of Lnikha and the village of Borovushka were previously part of the large collective farm "60 years of October", which was engaged in production of agricultural products and was reorganized in 1993 into Lnikha association of peasant farms (Lnikha APF) [9]. As a result of the transformations, the peasants of the Lnikha APF became the owners of agricultural land with cadastral number 54:24: 035801:79 with a declared area of $27,711,792$ sq.m. [10] on the basis of common shared ownership.

It shall be noted that the document - the basis for assigning the land of this category to the peasants was a state act certifying the ownership of land, life-long inherited possession, perpetual (permanent) use of land by citizens, enterprises, institutions, organizations or peasant (farmer) farms drawn up in accordance with Decree of the Council of Ministers of the RSFSR dated September 17, 1991 No. 493 [11]. As a rule, these are previously registered land plots, the registration of which was carried out before March 1, 2008, information about their boundaries is absent in the Unified State Register of Real Estate (USRN), the area is declared, that is, approximate [12]. The location of these agricultural lands is shown in Figure 1.

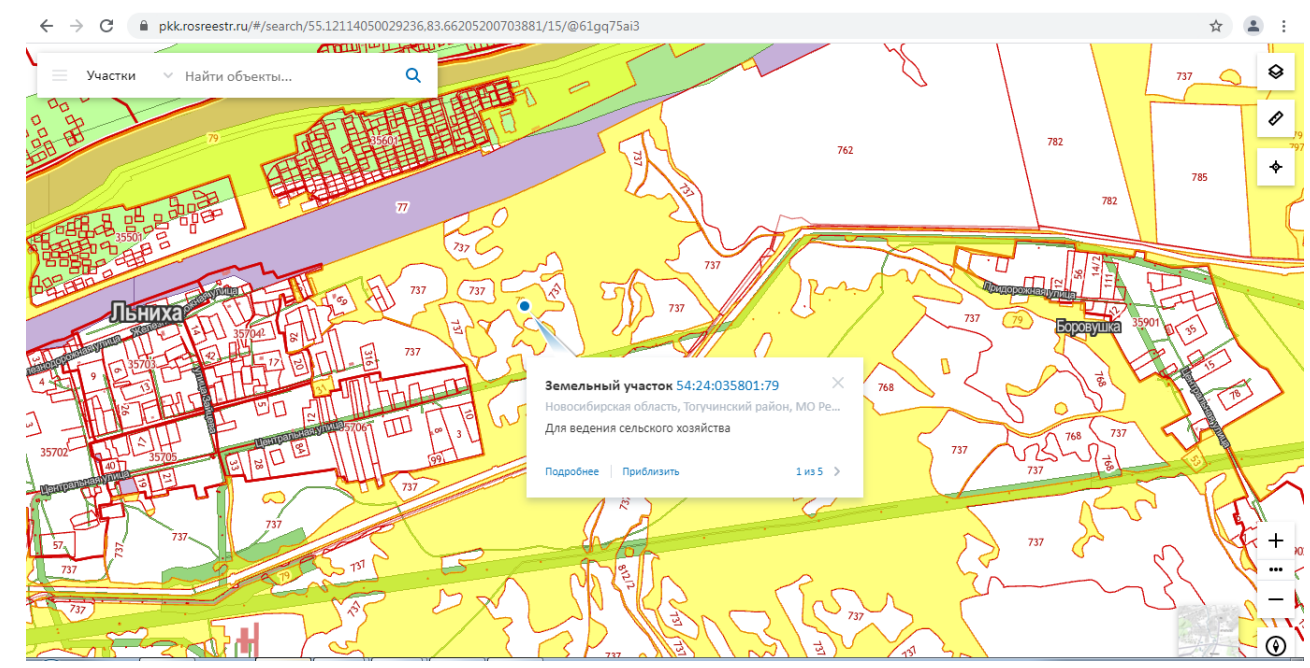

Fig. 1. Agricultural Lands of Lnikha APF.

If we refer to the public cadastral map of the Federal Service of State Registration, Land Register and Mapping [13], multiple inclusions in the considered agricultural lands of the forest fund lands are visually displayed. According to the soil map of the Novosibirsk region, these lands belong to the north-forest-steppe zone of the right bank of the Ob River. In geomorphological terms, the territory is an erosion-denudation upland, which is characterized by cone-shaped hills up to $390 \mathrm{~m}$ above sea level, steep deeply incised river valleys, slopes of more than $5^{\circ}$. From an agroecological point of view, these are highly erosional lands with a soil cover that includes dark gray and gray forest soils, podzolized 
chernozems, and meadow soils [14]. Specific features of natural conditions (rugged terrain, forested area) determine the rapid overgrowth of production fields and work sites with weeds and trees and shrubs in case of non-use of land for its intended purpose as a result of lack of agricultural activities $[15,16]$. This process can be clearly traced on satellite images provided in the Google Maps program (Fig. 2).

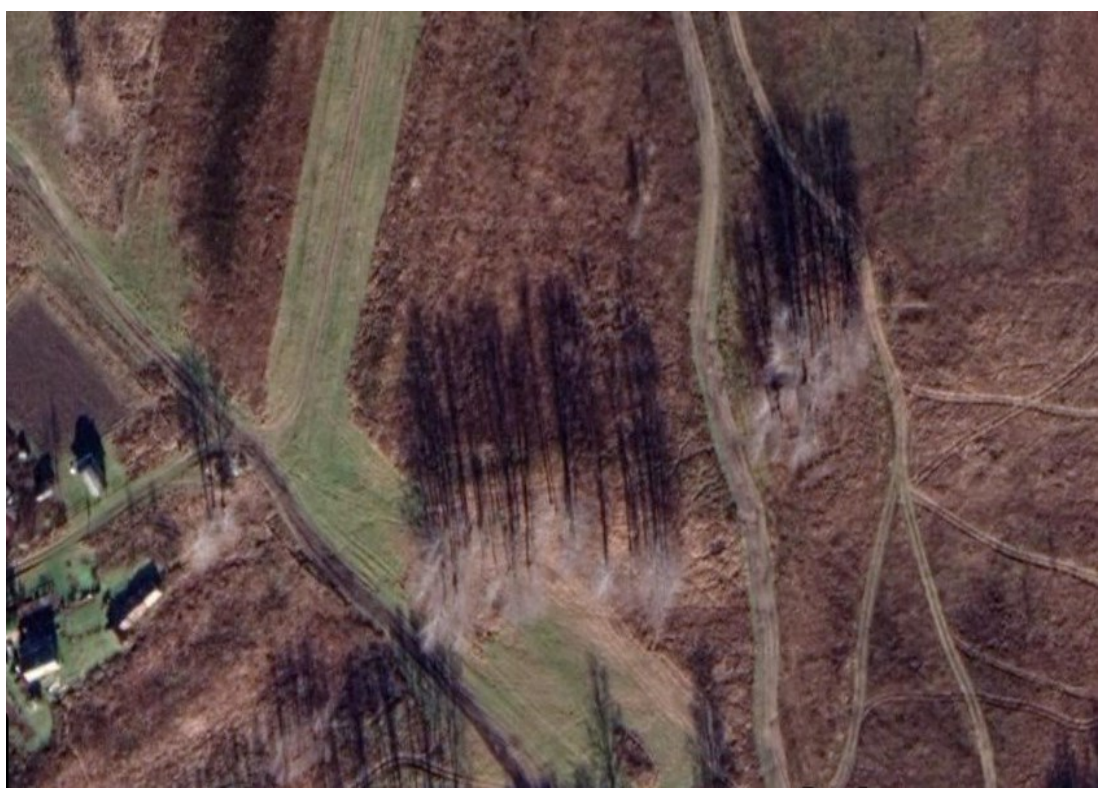

Fig. 2. Overgrowth of fields near village Borovushka, Toguchinsky district, Novosibirsk region (images of 2021, Google maps program, scale 1: 2500).

To identify the reasons for non-use of land, an analysis of the data of the All-Russian Population Census in different years was carried out (Table 1) [17, 18].

Table 1. Change in population in small settlements of Toguchinsky district of Novosibirsk region.

\begin{tabular}{|l|l|l|l|l|l|}
\hline District & Name of the settlement & 2002 & 2007 & 2010 & 2020 \\
\hline \multirow{2}{*}{ Toguchinsky } & Borovushka & 60 & 43 & 21 & N/A \\
\cline { 2 - 6 } & Lnikha & 546 & 542 & 589 & N/A \\
\hline
\end{tabular}

The NSO government, within the framework of a comprehensive program for the socioeconomic development of the Toguchinsky district in 2011-2015 and for the period until 2025, allocated funds for improvement and development of engineering infrastructure: the construction of a water supply system and the construction of antenna-mast structures for cellular communications in Borovushka and Lnikha, renovation of the house of culture and the Linikha library. In 2025, it is planned to perform reconstruction from the 4 th to the 2 nd category of the main road on the Bugotak - Lnikha - Repyevo section and to strengthen the railway tracks in order to establish protection against landslides [19]. Within the framework of the long-term target program "Development of gasification of the territory of settlements in the Novosibirsk region for 2012-2016", gasification schemes were developed for Lnikha village, Bugotak station, Bugotak village, and design estimates for gasification of Gorny settlement, Bugotak village, Bugotak station, Lnikha village in the amount of 25 million rubles. Wherein, there are no offers for investment activities in terms of revitalizing these settlements in the comprehensive program of socio-economic development of the Toguchinsky region in $2011-2015$ and for the period until 2025 [19]. Currently, there is a 
decrease in the number of students in rural schools, although Lnikha village is considered a remote village in which educational activities were previously carried out [20]. According to the electronic websites of real estate agencies, summer residents are settling in the villages of Borovushka and Lnikha, buying up village houses for recreation and summer seasonal residence $[21,22]$. Therefore, the village of Borovushka practically exists as a dacha society. In the village of Lnikha, rural life is still glimmering.

Now let's refer to more general official statistics characterizing the above quantitative components in the Toguchinsky district of the Novosibirsk region. According to the information of the administration of the Toguchinsky district of the Novosibirsk region, at present, in the territory of the Toguchinsky district of the NSO, the number of settlements of the district is 107 (villages, settlements, railway sidings). By 2002, the villages of Vyemka, Kazansky, Kazarma $132 \mathrm{~km}$ and the village of Agafonikha were abolished [9]. At the beginning of 2017, over 1.5 thousand settlements were registered throughout the Novosibirsk region. 56 of them are registered, but do not have a population. Since the 2010 census, more than 30 settlements have disappeared from the map of the Novosibirsk region as a result of the abolition [23].

The dynamics of the population in the regions under consideration in relation to the population of the city of Novosibirsk in the period from 2002 to 2020 [24] is reflected in Table 2.

Table 2. Change in the population in the Toguchinsky district of the NSO, as well as in the city of Novosibirsk in the period from 2002 to 2020.

\begin{tabular}{|c|c|c|}
\hline Periods & Novosibirsk & Toguchinsky district \\
\hline 2015 & $1,425,508$ & 65,515 \\
\hline 2015 & $1,621,835$ & 55,843 \\
\hline 2015 & $1,625,631$ & 55,427 \\
\hline
\end{tabular}

These data characterize the growth and concentration of the population in Novosibirsk, at the same time, there is a constant trend of population decline in the considered districts of the region. In general, the total number of the population in the Novosibirsk region is constantly increasing. So in 2002 the population of the NSO was 2,692,251 people, in 2007 — 2,647,195 people, in 2019 - 2,795,777 people, in 2020 - 2,798,170 people. [24]. Therefore, with a constant increase in the total population in the territory of the Novosibirsk region, there is a process of migration of the rural population to cities and regional centers. These trends indicate an outflow of labor resources and a reduction in the habitable space in the territory of the region's districts. These circumstances contribute to reduction of the cultivated areas of agricultural crops, leading to degradation of the remaining uncultivated agricultural lands. According to the results of the All-Russian Agricultural Census of 2016 for the period from 2007 to 2019 , the number of sown areas of agricultural crops is steadily decreasing in the territory of the NSO [25]. However, in 2020, the quantitative indicator of sown areas slightly increased compared to the previous year [26] (Table 3).

Table 3. Comparative table of the number of sown areas of agricultural crops by NSO for the period from 2007 to 2020 .

\begin{tabular}{|l|c|c|c|c|c|c|c|}
\hline Sown area & 2007 & 2010 & 2014 & 2017 & 2018 & 2019 & 2020 \\
\hline Ths ha & $2,419.0$ & $2,320.1$ & $2,376.4$ & $2,380.0$ & $2,226.6$ & $2,225.7$ & $2,272.0$ \\
\hline
\end{tabular}

Therefore, there is a trend of constant population growth in the Novosibirsk region: its number in 2020 compared to 2007 increased by $5.4 \%$. Wherein, the number of agricultural crops sown in the Novosibirsk region in 2020 decreased by $6.1 \%$ compared to 2007 . This is 147 thousand hectares of uncultivated agricultural land, in respect of which the process of degradation has begun. 


\section{Conclusions}

When summing up the study, we believe that it is possible to draw the following conclusions.

Formation of the Novosibirsk agglomeration in the territory of the Novosibirsk region is due to the created socio-economic situation, which entailed the migration of the rural population to regional centers and cities located near the city of Novosibirsk, which are most susceptible to its influence. These circumstances contribute to the process of overpopulation of these cities located in the territory of the Novosibirsk agglomeration and, in turn, to decrease in the rural inhabited space in the territory of municipalities located within the boundaries of the region's districts within the Novosibirsk agglomeration itself. Along with these processes, there is a decrease in the number of sown areas of agricultural crops on agricultural lands located in the territory of the Novosibirsk agglomeration, as well as in the territory of the entire Novosibirsk region. These circumstances contribute to the degradation of uncultivated agricultural land. It shall be noted that the described processes and the obtained study results do not differ from the general picture emerging in relation to agricultural land located throughout the territory of the Russian Federation.

Elimination of these negative processes accompanying the creation of agglomerations, in our opinion, is possible when developing a conceptual direction within the framework of a state scientifically grounded food security program, for example, "Agrarian Russia", the purpose of which could be phased structural and investment measures aimed at development of domestic agricultural production, restoration of suburban farmland and consolidation of the population in the inhabited territories. Any form of economic activity is acceptable here - from agricultural holdings and farms, up to individual private farmsteads with elements of agritourism. Wherein, reducing the consequences of sanctions pressure at the international level and eliminating trade barriers will increase the export of agricultural products abroad, which will also serve as a powerful incentive for development of this industry.

\section{References}

1. Law of the RSFSR dated November 23, 1990 No. 374-1 "On Land Reform".

2. Federal Law dated June 11, 2003 No. 74-FZ "On the Peasant (Farm) Economy".

3. Federal Law dated July 24, 2002 No. 101-FZ On the Turnover of Agricultural Land".

4. "Land Code of the Russian Federation" dated October 25, 2001 No. 136-FZ.

5. T. G. Nefedova, N.V. Mkrtchyan, Moscow University Bulletin, Series 5, Geography, 5, 58 (2017)

6. D. N. Baranov, Modern trends in development of the economy of urban agglomerations: monograph, 188 (2015) http://www.iprbookshop.ru/

7. P. A. Slovtsov, History of Siberia. From Ermak to Catherine II M.: Veche, 512 (2006)

8. Decree of the Government of the Novosibirsk Region dated March 19, 2019 No. 105-p "On the Strategy of Social and Economic Development of the Novosibirsk Region for the Period until 2030" https://www.nso.ru/

9. Wikipedia, https://ru.wikipedia.org.

10. Official website of the Federal Service of State Registration, Land Register and Mapping. Public cadastral map https://pkk.rosreestr.ru

11. Decree of the Council of Ministers of the RSFSR dated September 17, 1991 No. 493 "On the Approval of the Forms of the State Act on the Ownership of 1And, Life-Long Inherited Possession, Unlimited (Permanent) Use of Land"

12. Official website of the Federal Service of State Registration, Land Register and Mapping, https://rosreestr.gov.ru

13. Official website of the Federal Service of State Registration, Land Register and Mapping. Public cadastral map, https://pkk.rosreestr.ru 
14. Soil map of the Novosibirsk region. Scale 1:400000, 1987.

15. Decree of the Government of the Russian Federation dated September 18, 2020 No. 1482 "On Signs of Non-Use of Agricultural Land Plots for their Intended Purpose or Use in Violation of the Legislation of the Russian Federation."

16. N.I. Dobrotvorskaya, Bulletin of Novosibirsk State Agrarian University, 1(50), 1 (2019)

17. All-Russian population census 2010. The population of urban and rural settlements of the Novosibirsk region.

18. All-Russian population census of 2002. Population by rural settlements of the Novosibirsk region.

19. Comprehensive program of socio-economic development of Toguchinsky region for 2011-2015 and for the period up to 2025, https://www.nso.ru

20. Electronic version of the regional regional newspaper Toguchinsky Bulletin, 24 (2016) http://www.toguchin.nso.ru

21. Real estate agency Onrealt, https://onrealt.ru

22. NGS real estate, https://novosibirsk.n1.ru

23. Register of settlements of the Novosibirsk region. Newspaper Soviet Siberia, 146 (2007)

24. Official site of Novosibirskstat, https://novosibstat.gks.ru/

25. Federal State Statistics Service. All-Russian Agricultural Census 2016: https://rosstat.gov.ru/

26. Official site of the Ministry of Agriculture of the Novosibirsk Region, http://mcx.nso.ru/page/ 